\title{
Introduction to the First Issue of the Journal of Chan Buddhism: East Asian and Global Perspectives
}

Welcome to the first issue of the Journal of Chan Buddhism: East Asian and Global Perspectives ( Јсв for short). This is the first academic journal outside China, Japan, and Korea focused on cutting-edge research across many disciplines concerning the religious traditions of Chinese Chan, Japanese Zen, Korean Sŏn, and Vietnamese Thiên Buddhism. All aspects of Chan/Sŏn/Zen/ Thiên studies will be represented by forthcoming issues of JCB including, but not limited to the history of religions; literary studies; Dunhuang studies; Tibetan and Tangut language Chan studies; doctrinal studies; art historical perspectives; institutional history; anthropological research; and comparative, philosophical studies. ЈСв joins an elite group of academic journals devoted to the study of Chan Buddhism in China with research articles in Chinese (Chinese Chan Studies, Zhonghua Chanxue 中華禪學), Zen Buddhism with articles in Japanese (journals published by The Institute for Zen Studies at Hanazono University, Hanazono daigaku Zen bunka kenkyūjo 花園大学禅文 化研究所 and at Komazawa University, under the direction of the Department of Zen Buddhist Studies, Komazawa daigaku Zen kenkyūjo), and Korean Sŏn with articles in Korean (Sŏn Garden, Sŏnwŏn 禪苑 and Studies of Sŏn Culture, Sŏn munhwa yŏn'gu 禪文化研究), among others. But JCB is the first academic journal dedicated to a multifaceted, cross-cultural, and transregional study of these traditions in general. This first double issue includes research articles by a select group of scholars. Addressing new approaches to the study of Chinese Chan Buddhism, we are pleased to include articles by T.H. Barrett, Barend ter Haar, Lin Peiying, Albert Welter, and Wang Song, while Juhn Y. Ahn presents a fresh perspective on an issue of Korean Sŏn. JCB's second volume will include articles covering Zen and Tangut language Chan literature.

Because so much ground-breaking research with new materials and novel or transdisciplinary approaches to the study of Chan/Sŏn/Zen/Thiên Buddhism is being published by scholars and researchers in China, Japan, Korea, Vietnam, Europe, North America, and Oceania, forthcoming issues will include reviews of books about Chan/Sŏn/Zen/Thiên studies published in languages other than English. Readers will already find among the research articles in this inaugural issue that we endeavor to include translations into 
English of cutting-edge research published in Asian and European languages. Because it can be difficult to keep up with landmark research about Chan/Sŏn/ Zen/Thiên Buddhist studies published in so many languages, we will also occasionally publish English translations of relevant articles originally published in Chinese, Japanese, Korean, and in Vietnamese. The editors welcome submissions in English of original research papers, occasional conference reports, and critical book reviews.

We would like to take this opportunity to introduce our editorial staff: Dr. Chen Jinhua (University of British Columbia, Chief Editor), Dr. George A. Keyworth (University of Saskatchewan, co-editor), and Dr. Steffen Döll (University of Hamburg, co-editor). We are delighted to be publishing JСв with Brill, and would like to especially thank Inge Klompmakers and Wendy Logeman for their support and professionalism. We would also like to thank the Tianzhu Charitable Foundation for supporting this project.

Finally, we would like to dedicate this issue to the memory of Yanagida Seizan (1922-2006), Antonino Forte (1940-2006), John R. McRae (1947-2011), and our many remarkable teachers.

The editors

October 2020 